\title{
Swallowing function after severe COVID-19: early videofluoroscopic findings
}

\author{
Aude Lagier $^{1}(\mathbb{D}) \cdot$ Evelyne Melotte $^{2} \cdot$ Mélanie Poncelet $^{3} \cdot$ Sarah Remacle $^{1} \cdot$ Paul Meunier $^{4}$
}

Received: 9 November 2020 / Accepted: 26 November 2020 / Published online: 3 January 2021

(c) The Author(s), under exclusive licence to Springer-Verlag GmbH, DE part of Springer Nature 2021

\begin{abstract}
Introduction The aim of this paper is to describe the early findings of swallowing analysis with videofluoroscopy of swallowing (VFS).

Methods The 21 first patients (14 men and 7 women) who recovered from ARDS in context of COVID-19 were referred to VFS just before to maximum 14 days after their discharge from ICU. The swallowing impairments and the physiopathologic mechanism of them were prospectively analyzed by two swallowing experts: one radiologist, and one phoniatrician using penetration-aspiration scale (PAS) score.

Results Nineteen out of 21 presented impairment in their swallowing function. Sixteen patients presented direct penetration or inhalation. All but one were silent. Some stases were also observed in 13 patients. Five patients presented secondary penetration/aspiration, among these inhalations, and all were silent. The most frequent findings are the delayed pharyngeal phase, the reduced propulsion of the tongue root, the posterior oral leaks, the default of laryngeal closure, and the impaired pharyngeal peristaltism.

Discussion The very high prevalence of swallowing disorders with inhalation and the lack of protective reflexes are the main findings. This emphasizes the need of high caution with bedside screening in these patients with severely injured lungs.
\end{abstract}

Keywords COVID-19 $\cdot$ Coronavirus $\cdot$ Dysphagia $\cdot$ Swallowing disorders $\cdot$ Acute respiratory distress syndrome

\section{Introduction}

The pandemic of COVID-19 emerged few months ago. The question of the intensive care unit availabilities has been critical due to the possible occurrence of acute respiratory distress syndrome (ARDS) in 8-29\% of patients [1]. In the $5 \%$ most severe cases, respiratory support could include mechanical ventilation [1] through oro-tracheal intubation or tracheostomy. Post-extubation dysphagia is reported in more than $40 \%$ of patients in intensive care units independently from their pathology [2]. In COVID-19 patients

Aude Lagier

aude.lagier@chuliege.be

1 Service D'ORL, CHU de Liège, Avenue de l'hôpital, 1, 4000 Liège, Belgium

2 Service de Médecine Physique Et Réadaptation, CHU de Liège, Liège, Belgium

3 Service de Pneumologie, CHU de Liège, Liège, Belgium

4 Service de Radiologie, CHU de Liège, Liège, Belgium where the lungs are severely injured, it is especially critical to identify dysphagic patients [3]. At the same time, several recommendations on the dysphagia assessment have been published to reduce the exposition and contamination of the healthcare workers. All recommendations proposed to post-pone pharyngo-laryngeal fiberscopy [4], and thus fiber-endoscopic evaluation of swallowing [5]. The videofluoroscopy of swallowing appeared as a safer process with less exposure to virus, and presents a high reliability in the detection of aspiration [5].

For now, there are no data available on the findings of VFS or other objective swallowing tests at the early stages of the recovery in post-extubation COVID-19 patients who required intensive care for ARDS. We propose to report these findings in the 21 first patients examined by VFS in a tertiary care center. 


\section{Materials and methods}

All patients who had been intubated for mechanical ventilation for $>48 \mathrm{~h}$ in the context of severe COVID-19 were referred to radiology department for VFS when they were conscious and able to maintain a sitting position for $15 \mathrm{~min}$, 0-14 days after their relieve from ICU. This is a retrospective study, consistent with the current ethical laws in Belgium, of the clinical procedure adopted in the COVID-19 context.

Videofluoroscopy: all patients were examined in seated position. After blank X-rays, the procedure included fluoroscopy registrations (less irradiating) in face and profile incidences. The profile incidence was used to assess the swallowing function. The swallowing tests include swallowing of barium with several levels of thicknesses [6]: IDDSI 2 first for the analysis of the mechanisms of swallowing, IDDSI 0 to increase the sensibility to aspiration, and IDDSI 5 (soft cake in barium) to increase the sensibility to stases. All VFS were analyzed by a laryngologist specialized in swallowing disorders and a radiologist specialized in VFS, the results provided were a consensus between them. If some impairment is highlighted with a bolus, it is considered as impaired. The penetration-aspiration scale (PAS score) [7], and qualitative assessment of stases location, and of the mechanisms of swallowing were performed.

\section{Results}

\section{Patients}

Twenty-one patients (14 men and 7 women) were referred for VFS 0-14 days after their discharge from ICU. SARS$\mathrm{CoV}-2$ research in nasopharynx was negative for all of them. All had a history of intensive care treatment with oro-tracheal intubation $>48 \mathrm{~h}$ for COVID-19 pneumopathy. The mean age was $63(\min 45, \max 76)$.
The medical history found hypertension $(n=9)$, obesity $(n=8)$, diabetes $(n=7)$, sleep apnea hypopnea syndrome $(n=5)$, neurological disease (vascular: 4, Parkinson disease: 1 , and congenital palsy: 1$)$, and coronaropathy $(n=2)$. Two patients reported swallowing disorders' history.

The mean duration of the intensive care stay was 30 days. The mean duration of oro-tracheal intubation was 17 days, five patients had a tracheostomy at the VFS, and one who had had a tracheostomy was already decannulated. Eight out of the 21 patients had experienced an extubation failure with subsequent re-intubation. Fourteen patients needed ventral position for ventilation, with a mean duration of 5 days.

\section{VFS findings}

Two patients showed no significant swallowing disorder, the remaining 19 out of 21 presented impairment in their swallowing function.

Sixteen patients presented direct penetration or inhalation. PAS scores are summarized in Table 1. All but one were silent: two patient who had vestibular penetration at the initiation of the swallow ejected the barium while swallowing but did not cough, and one patient who had tracheal inhalation coughed lately without any efficiency for the ejection.

Some stases were also present in 13 patients. Their locations are summarized in Table2. Five patients presented secondary penetration/aspiration due to the stasis. Among these inhalations, all were silent (Table 3).

Table 2 Distribution of the location of the stases

\begin{tabular}{lc}
\hline Stasis location & $\begin{array}{l}\text { Number of } \\
\text { patients }\end{array}$ \\
\hline None & 8 \\
Vallecula only & 3 \\
Hypopharynx only & 0 \\
Vallecula and hypopharynx & 10 \\
\hline
\end{tabular}

Table 1 Distribution of the PAS scores for direct penetrations and inhalations 
Table 3 Distribution of the PAS score for secondary penetration and aspiration due to stases

\begin{tabular}{l} 
Penetration-aspiration score \\
\hline 1. Material does not enter the airway \\
2. Material enters the airway, remains above the vocal folds, and is ejected from the airway \\
3. Material enters the airway, remains above the vocal folds, and is not ejected from the airway \\
4. Material enters the airway, contacts the vocal folds, and is ejected from the airway \\
5. Material enters the airway, contacts the vocal folds, and is not ejected from the airway \\
6. Material enters the airway, passes below the vocal folds, and is ejected into the larynx or out of the airway \\
7. Material enters the airway, passes below the vocal folds, and is not ejected from the trachea despite effort \\
8. Material enters the airway, passes below the vocal folds, and no effort is made to eject
\end{tabular}

Table 4 Distribution of the impaired mechanisms of swallowing

\begin{tabular}{lc}
\hline Impaired mechanism & $\begin{array}{l}\text { Number of } \\
\text { patients }\end{array}$ \\
\hline Lips leaks & 3 \\
Posterior oral leaks & 9 \\
Increased duration of oral phase/impaired initiation of & 5 \\
$\quad$ oral phase & 15 \\
Delayed pharyngeal reflex & 0 \\
Reduced elevation of the velum & 0 \\
Reduced elevation of the larynx & 12 \\
Reduced propulsion of the tongue root & 9 \\
Default of laryngeal closure & 7 \\
Impaired pharyngeal peristaltism & \\
\hline
\end{tabular}

The impaired mechanisms are summarized in Table 4. The most frequent findings are the delayed pharyngeal phase, the reduced propulsion of the tongue root, the posterior oral leaks, the default of laryngeal closure, and the impaired pharyngeal peristaltism.

\section{Discussion}

This is the first study describing the objective swallowing findings in a series of patients at early stage of recovery from severe COVID-19. The very high prevalence of swallowing disorders with inhalation and the lack of protective reflexes are the main findings. The prevalence of silent aspiration in post-extubation for other pathology than COVID-19 is reported to be $25 \%$ in the literature [3, 8 ], compared to $80 \%(16 / 20)$ in the present study. The absence of history of swallowing disorders is not protective as only two patients reported previous dysphagia in our population. It emphasizes the necessity of a very reliable screening for dysphagia in this context of disturbed lung function.
Clinical swallowing assessment is not fully reliable in post-extubation patients with non-COVID-19 acute respiratory failures [9]. Furthermore, in the context of epidemic, the healthcare worker has to respect distance from the patient, to wear personal protective equipment and avoid most of the swallowing tests which are aerosol-generating [3]. It is then likely that the quality of the screening is significantly decreased. These reasons lead our team to propose VFS when speech therapists were asked to screen these patients in ICU.

In this context, only the VFS seemed to complete the reliability in swallowing disorder diagnosis and the safety for the healthcare workers as the patients stay distant from the examiner. All tests of SARS-CoV2 presence in the nasopharynx of the patients had returned negative before they were referred because of the duration of their stay in ICU. They were then considered at low risk of contamination. The main problem with VFS is the necessity for the patient to stay in a sitting position during the examination.

The reported mechanisms of post-extubation dysphagia in non-COVID-19 patients are $[3,10]$ :

- Oropharyngeal and laryngeal trauma.

- Neuromuscular weakness of the muscles involved in swallowing function.

- Reduced sensibility of the upper respiratory tract, supposed to recover around 7 days after extubation.

- Altered sensorium related to the development of delirium.

- Gastroesophageal reflux which is increased by the nasogastric tube, lying position and sedation drugs.

- Dyssynchronous breathing and swallowing mainly in the context of tachypnoea.

All these mechanisms were present in the studied population, at different intensities and with some particularities. The dyssynchronous breathing and swallowing was not found in our population, probably because the acute respiratory problem was solved at the moment of the examination. 
No delirium was noticed at the moment of the examination. On the contrary, all the patients were fed with a nasogastric tube, with the risk of gastroesophageal reflux. The history of extubation failure with re-intubation and the duration of oro-tracheal intubation are significantly associated with dysphagia [11] and this duration was very high in our population. It is likely that the ventral position also increased the oropharyngeal and laryngeal trauma. The high duration of sedation also increased the risk of neuromuscular weakness with impaired lingual and/or pharyngeal propulsion of the bolus and stases. The sensibility of the upper respiratory tract was probably reduced, explaining the most frequent findings of VFS with both delayed pharyngeal phase of swallowing and lack of protective reflexes, despite the delay from extubation $>7$ days. This may be due to direct neurological pathogenesis of the SARS-CoV2, but it is hypothetic and this study does not allow to ascertain it. The virus is known to be neurotropic and some authors hypothesized that it could retrogradely travel from the vagus endpoints in the infected organs to the solitary tract in the brainstem, which is very important for the sensibility of the pharynx and the larynx [12]. Some others emphasized that all the swallowing network including cortical, subcortical and brainstem structures as well as peripheral nerves and muscles may be targeted by the virus [13].

Obviously, this study has some limitations. The first one is that it is descriptive and based on a retrospective design as the VFS was performed in the clinical management of the patients and not in a prospective way. Nevertheless, facing to the emerging pathology, we decided to prospectively collect the data when the VFS was performed. Due to this method, there may be some bias in the recruitment of the patients. The number of patient is not very high but the profiles of the patients are quite homogeneous and so are the VFS findings. The other weakness is the lack of control group which prevent to consider COVID-19 patients as different from patient with as long ICU stay with oro-tracheal intubation, but the constitution of this group may be problematic: other patient undergo tracheostomy earlier, and their own pathology may importantly impact the swallowing function.

\section{Conclusion}

Patients recovering from severe COVID-19 with long-lasting stay in ICU do present severe swallowing disorders with high incidence of silent aspiration. Due to their reduced lung function, aspiration can worsen their clinical situation. It is necessary to be very cautious with the bedside dysphagia screening, keeping in mind that its sensibility to silent aspiration is limited and that its quality is decreased by the protective measures in epidemic context. It seems better to delay the screening and to propose VFS when the patient is able to undergo it.

\section{Compliance with ethical standards}

Conflict of interest None to declare.

Research involving human participants Yes, retrospective study.

Informed consent Retrospective study, not applicable.

\section{References}

1. Jiang F, Deng L, Zhang L, Cai Y, Cheung CW, Xia Z (2020) Review of the clinical characteristics of coronavirus disease 2019 (COVID19). J Gen Intern Med 35:1545-1549. https://doi.org/10.1007/s1160 6-020-05762-w

2. Brodsky MB, Pandian V, Needham DM (2020) Post-extubation dysphagia: a problem needing multidisciplinary efforts. Intensive Care Med 46:93-96. https://doi.org/10.1007/s00134-019-05865-x

3. Frajkova Z, Tedla M, Tedlova E, Suchankova M, Geneid A (2020) Postintubation dysphagia during COVID-19 outbreak-contemporary review. Dysphagia 35(4):549-557. https://doi.org/10.1007/s0045 5-020-10139-6

4. Rameau A, Young VN, Amin MR, Sulica L (2020) Flexible laryngoscopy and COVID-19. Otolaryngol Head Neck Surg 162:813-815. https://doi.org/10.1177/0194599820921395

5. Mattei A, Amy de la Bretèque B, Crestani S, Crevier-Buchman L, Galant C, Hans S, Julien-Laferrière A, Lagier A, Lobryeau C, Marmouset F, Robert D, Woisard V, Giovanni A (2020) Guidelines of clinical practice for the management of swallowing disorders and recent dysphonia in the context of the COVID-19 pandemic. Eur Ann Otorhinolaryngol Head Neck Dis 137:173-175. https://doi. org/10.1016/j.anorl.2020.04.011

6. Cichero JA, Lam P, Steele CM, Hanson B, Chen J, Dantas RO, Duivestein J, Kayashita J, Lecko C, Murray J, Pillay M, Riquelme L, Stanschus S (2017) Development of international terminology and definitions for texture-modified foods and thickened fluids used in dysphagia management: The IDDSI framework. Dysphagia 32:293-314. https://doi.org/10.1007/s00455-016-9758-y

7. Rosenbek JC, Robbins JA, Roecker EB, Coyle JL, Wood JL (1996) A penetration-aspiration scale. Dysphagia 11:93-98. https://doi. org/10.1007/BF00417897

8. Ajemian MS, Nirmul GB, Anderson MT, Zirlen DM, Kwasnik EM (2001) Routine fiberoptic endoscopic evaluation of swallowing following prolonged intubation: implications for management. Arch Surg 136:434-437. https://doi.org/10.1001/archsurg.136.4.434

9. Lynch YT, Clark BJ, Macht M, White SD, Taylor H, Wimbish T, Moss M (2017) The accuracy of the bedside swallowing evaluation for detecting aspiration in survivors of acute respiratory failure. $\mathrm{J}$ Crit Care 39:143-148. https://doi.org/10.1016/j.jcrc.2017.02.013

10. Macht M, Wimbish T, Bodine C, Moss M (2013) ICU-acquired swallowing disorders. Crit Care Med 41:2396-2405. https://doi. org/10.1097/CCM.0b013e31829caf33

11. Brodsky MB, Gellar JE, Dinglas VD et al (2014) Duration of oral endotracheal intubation is associated with dysphagia symptoms in acute lung injury patients. J Crit Care 29:574-579. https://doi. org/10.1016/j.jcrc.2014.02.015

12. Tassorelli C, Mojoli F, Baldanti F, Bruno R, Benazzo M (2020) COVID-19: what if the brain had a role in causing the deaths? Eur J Neurol 27:e41-e42. https://doi.org/10.1111/ene.14275.10.1111/ ene. 14275 
13 Dziewas R, Warnecke T, Zürcher P, Schefold JC (2020) Dysphagia in COVID-19 -multilevel damage to the swallowing network? Eur J Neurol 27:e46-e47. https://doi.org/10.1111/ene.14367
Publisher's Note Springer Nature remains neutral with regard to jurisdictional claims in published maps and institutional affiliations. 